\title{
Next steps towards universal health coverage call for global leadership
}

\author{
(c) (1) @ $\circledast$ OPEN ACCESS
}

Gerald Bloom and colleagues argue that the G20 is uniquely placed to facilitate crucial actions to accelerate progress towards universal health coverage

\author{
Gerald Bloom research fellow ${ }^{1}$, Yasushi Katsuma director of global health affairs and governance ${ }^{2}$ \\ ${ }^{3}$, Krishna D Rao associate professor ${ }^{4}$, Saeda Makimoto executive senior research fellow ${ }^{5}$, Jason \\ D C Yin research assistant ${ }^{6}$, Gabriel M Leung Zimmern professor of population health ${ }^{6}$
}

${ }^{1}$ Institute of Development Studies, London, UK; ${ }^{2}$ Waseda University, Tokyo, Japan; ${ }^{3}$ Institute for Global Health Policy Research, National Center for Global Health and Medicine, Tokyo, Japan; ${ }^{4}$ Johns Hopkins Bloomberg School of Public Health, Baltimore, Maryland, USA; ${ }^{5}$ JICA Research Institute, Tokyo, Japan; ${ }^{6}$ University of Hong Kong, Hong Kong SAR, China

Universal health coverage (UHC) has been identified as a priority for international development by the G20, the World Health Organization, and the United Nations General Assembly. Since it was explicitly incorporated into the sustainable development goals (SDGs) as target 3.8, much effort has been expended on promoting UHC. Here we focus on four areas that, on current trajectories, are unlikely to achieve sufficient progress to meet the target. These are also areas for which G20 can provide substantial leverage: the principle of "leaving no one behind," particularly in migrant health and genuine support for primary care; reliable domestic financing, which requires enlightened leadership and deliberate dialogue between finance and health sectors; harnessing and regulating medical and technological innovation; and mutual learning and harmonised aid among donor countries. We call on G20 leaders, who will meet in Osaka in June 2019, to take concrete action on these issues.

This article is based on a policy brief prepared by a working group convened by the Government of Japan as host of the Think 20 summit in Tokyo in May 2019. ${ }^{1}$ Our work has received input from a wide ranging global group of thought leaders, some of whom represent civil society, including patients and the general public.

\section{Leaving no one behind}

Substantial inequities in access to affordable quality healthcare remain both within and between countries. Vulnerable populations face greater morbidity and premature mortality from easily preventable and treatable causes. Such inequities also threaten human security. ${ }^{2}$

\section{Strong primary healthcare for health equity}

Strong primary healthcare systems are effective in reducing inequities of access by providing local services and facilitating continuous, comprehensive, and coordinated care. ${ }^{3-5}$ The 1978 Alma Ata declaration, which was reaffirmed in Astana in 2018, recognised the importance of primary care in advancing universal health coverage. Nevertheless, progress can be difficult. For instance, China's policy goal of having two to three primary care doctors for every 10000 population by 2020 has met with challenges in recruiting, training, and keeping adequate and sufficient doctors. $^{6}$

Strengthening primary healthcare systems to reduce inequities requires action on many fronts, but two are particularly important for governments. Firstly, domestic financing and development aid should emphasise investments in essential services that can be provided at the community level and by basic health workers. Making essential medicines universally affordable and available is critical. The emergence of HIV/AIDS and resurgence of tuberculosis and malaria have focused global funding on control of these diseases. Although substantial progress has been achieved, this was often accomplished by building parallel financing and delivery systems. ${ }^{7}$ G20 and development partners should bring about a renewed focus on strengthening primary care systems within global disease control programmes. In particular, G20 should promote better 
measurement of the performance of primary care systems and support and expand ongoing efforts such as the Primary Healthcare Performance Initiative (https://improvingphc.org/).

Secondly, population ageing and the growing burden of non-communicable diseases pose new challenges to national health systems. Two thirds of the world's older people live in low and middle income regions. ${ }^{8}$ The preoccupation with infectious diseases and reproductive health has shaped the organisation of primary care systems in many countries. Older people, however, are more likely to have non-communicable diseases that require sustained care. The development assistance policy of G20 members should encourage reorienting of primary healthcare systems towards providing cost effective interventions that are health promoting, preventive, and curative, such as those identified in the World Bank's Disease Control Priorities. ${ }^{9}$

\section{Health of migrants and healthcare worker migration}

Access to affordable quality healthcare is an important concern for all vulnerable groups. However, global migration, and especially migrant workers, poses a unique and so far neglected challenge to progress towards universal health coverage.

There were 258 million migrants in 2017 , representing $3.4 \%$ of the world's population (fig 1 ). ${ }^{10}$ Work is one of the main motivations behind global migration, accounting for $64 \%$ of all migrants (164 million) in 2017 (fig 1). ${ }^{11}$ Although the UN General Assembly endorsed the Global Compact for Safe, Orderly and Regular Migration in 2018, supporting the right of migrants to healthcare and encouraging countries to incorporate their health needs into policies, the health implications associated with migration are still given too little attention. ${ }^{12}$

G20 members, many of which are important destination countries for migrants ${ }^{13}$ should spearhead intergovernmental action to establish reliable information systems on migrants. This includes having an agreed set of standardised, publicly available migration indicators that source and destination countries collect. ${ }^{14}$ Routine national statistical systems must also include and identify migrant populations. This can help governments understand the scale of migration, develop evidence based policies, and know the extent to which refugees and labour migrants are able to access health and other social services. $^{1014}$

The productivity of migrant workers is tied to their health, and it therefore benefits the host country to invest in their health. ${ }^{15}$ In addition, the documented migrant labour workforce contributes to the host economies through taxation. Many migrant workers take on jobs that have poor work environments, placing them at a higher health risk, but they may not have access to care because of government policy, lack of citizenship, or clarity on legal status. ${ }^{16}$

Migrant workers should be offered similar access to health and social security benefits as local workers. ${ }^{12}{ }^{17}$ Their health benefits should, as far as possible, be coordinated by both source and destination countries. G20 should also explore extending health benefits to the families of migrant workers and making health benefits portable so that migrants returning home can "accrue" their health coverage benefits such as insurance status and premium levels. ${ }^{18}$ Since G20 countries would have to bear the attendant costs, none of these proposals, however indisputably just and fair, are going to be easily accepted, especially given the alarming global spread of populist, even nativist, views.

Health systems in many countries are also reliant on migrant workers (fig 2). The migration of healthcare workers from resource poor to high income countries affects the ability of source countries to benefit from their investments in education of health professionals. At the same time, migration offers healthcare workers opportunities for better compensation and professional development. In 2010, WHO adopted the Global Code of Practice on the International Recruitment of Health Personnel to encourage ethical and fair practices. ${ }^{21}$

G20 countries need to systematically measure mobility of the health workforce. ${ }^{21}$ Additionally, G20 is uniquely placed to facilitate a shared understanding of the complex web of relationships between workforce migration, health workforce needs, and workforce planning and production at country and global levels. This will require engagement with multiple sectors: education, health, and labour ministries within national governments; international recruitment stakeholders; health professional groups; and UN agencies, including WHO and the International Labour Organisation.

\section{Prioritising reliable domestic financing and cost effective interventions}

Health systems will increasingly need to adapt to rapid and interconnected social and technological changes that will have a big effect on the demand for health services and the capacity to pay for them. Population ageing, the growing burden of non-communicable diseases, developments in medical technologies, and the multiplicity of communication channels are driving increasing expectations for medical care. This is happening at a time when many countries are experiencing fiscal stagnation linked to population ageing and changes in the labour market in favour of the informal economy. Countries are at risk of shocks related to climate change, economic transitions, pandemics, and other threats. These can affect both the demand for health services and the resources available to pay for them.

Many G20 countries are implementing innovative approaches for coping with rapidly increasing demand or challenges associated with fiscal stagnation. ${ }^{22-25}$ Although mobilising domestic resources to reliably finance needed healthcare is crucial, fiscal discipline in resource allocation and spending is equally critical to ensure long term sustainability.

G20 members have mechanisms to ensure that less developed regions of their countries receive appropriate financial support for health services. Some also provide health development assistance to low income countries. This support must be maintained and should take into account big changes in economic development. Several countries and regions are experiencing increases in average income, especially in rapidly growing urban areas and in resource rich localities. Their governments face special challenges in establishing effective and reliable mechanisms for financing health services that meet the needs of all. G20 members should reallocate health development assistance gradually to areas with the greatest need while supporting other areas to become self sufficient. This will include providing opportunities for mutual learning about effective strategies for health finance, support for strengthening health financing institutions, and tapering of support to avoid sudden shocks.

Increased health finance needs to be complemented by measures to ensure that resources are used well. One important area for intervention is access to effective and appropriate drugs. This requires measures to reduce their cost to patients and ensure that medicines are good quality and used well. This is especially important for antimicrobials because of the health consequences of treatment failure and the risk of resistance. Commitments by G20 to invest in antimicrobial drug discovery must be 
complemented by measures to increase access to treatment and improve stewardship of such drugs. ${ }^{26-29}$ Low income communities require financial support to purchase and distribute these drugs, as already occurs for treatments of tuberculosis, malaria, and HIV/AIDS. Measures to reduce the cost of drugs should be complemented by actions to ensure appropriate use, such as introducing treatment guidelines, agreements by drug companies to end incentives that encourage a high volume of sales, and public information campaigns.

The development of affordable and good quality point-of-care diagnostics can also encourage rational use. G20 should support the incorporation of these measures into national action plans as well as development cooperation plans for tackling infectious diseases and making progress towards UHC. Figure 3 shows how the WHO Western Pacific Region UHC action framework and the WHO antimicrobial resistance global action plan converge resulting in actionable policies that governments could pursue.

\section{Harnessing innovation judiciously}

Technological innovations in healthcare (pharmaceuticals, diagnostics, devices, etc) and in information and communication technologies could substantially change the way health services are provided. ${ }^{3031}$ Markets on their own are unlikely to produce innovations that increase access to safe and affordable services at scale and on a sustainable basis. Governments can contribute by creating a regulatory environment that supports research and development, encourages equitable access to technologies and medicines, and protects the public against unintended harms. UHC2030, a global partnership (https://www.uhc2030.org/), has established a private sector constituency to explore ways that non-state organisations can contribute to efforts to meet healthcare needs at scale and the implications for government action. G20 should encourage and support this.

One important area of innovation is in information and communications technologies, which hold enormous potential for increasing access to health information and care. ${ }^{3031}$ Bilateral development agencies and international philanthropies have invested in several successful pilots, and some large companies are investing heavily in the development of digital health services, but these have had limited effect on access to health services. ${ }^{32-34} \mathrm{Box} 1$ lists some developments that are likely to produce change. ${ }^{35}$

\section{Box 1: Effect of growing digitisation on the health sector}

- Rapid falls in the cost of smartphones and access to the internet and in the development of low cost diagnostic technologies

- Development of smartphone applications that link information on symptoms and diagnostic indicators to advice on treatment

Emergence of business models that enable information platforms to link to suppliers of goods, such as drugs, at scale

- Creation of platforms that maintain secure personal health records and enable people to link to different types of healthcare provider

Government action is needed to ensure that digital health and other information based technologies contribute to UHC, rather than to meeting the needs of a privileged minority, expanding markets for suppliers of drugs or diagnostic devices, or generating data for commercial use. Governments can work with development agencies to accelerate progress by shifting investment from pilots to routine efforts and by testing new forms of collaboration between public and private sectors.

Digital health technologies are potentially disruptive: they can lead to new kinds of partnership between organisations in the health, knowledge, and telecommunications sectors; alter the relationships between individuals, their families, and usual providers of healthcare; and create new kinds of distance services within countries and across borders. Recent experience in other sectors has shown that incremental changes can lead to a tipping point and subsequent transformation. In some cases they have led to the rapid growth of large and very powerful corporations, which have strongly influenced subsequent developments. It is important that governments put in place a robust framework that can meet these new regulatory challenges 3135 (box 2) before that point is reached. We recommend that G20 establish a working group involving all relevant ministries to work with their supranational interlocutors, as well as private industry, to review opportunities and challenges associated with the rapid development of digital health services and the deployment of disruptive technologies. ${ }^{36}$ This group could identify areas for collaboration in accelerating progress towards UHC and for establishing regulatory standards for digital health services and systems. It could also identify the appropriate global agency to support ongoing work on this issue.

Box 2: Regulatory challenges in scaling up digital health

- How can new health platforms be influenced to prioritise the needs of the public rather than commercial interests?

- To what extent should online medical advice be regulated and should algorithms be produced and made available as public goods?

- Who should own the data from users of digital health services and who should modify treatment algorithms on the basis of these data?

- How can personal privacy be taken into account?

-What are the implications for the regulation of healthcare professionals?

\section{Coordinated international cooperation for UHC}

\section{Common UHC monitoring mechanisms}

Use of the same metrics would make cross-country data on monitoring UHC directly comparable, but this does not always happen, mostly because of variable technical competence and non-standardised approaches in data collection.

The SDG target on universal health coverage sets out two specific indicators to monitor progress in coverage of essential health services and financial protection. The methods and country data requirements of these indicators are already defined, ${ }^{37}$ and the current priority is to develop a common operational protocol that can be shared between countries, especially those in resource limited settings so that all member states can produce directly comparable statistics. A globally shared mechanism of technical support, sufficiently contextualised to allow for between-country differences in data availability, including data disaggregation to capture equity perspectives and other variabilities, should be established.

In addition to formally tracking progress through the SDG indicators, sharing of on-the-ground practical experience is important. G20 should help other countries strengthen national monitoring and evaluation capacities and enhance multistakeholder dialogue on policy. Importantly, G20 should provide direct and in-kind support to academic institutions in their own countries to further develop a global technical support network. Some efforts are already under way to set up common UHC monitoring, such as the Health Data Collaborative (https: //www.healthdatacollaborative.org/). 


\section{Mutual learning platforms at global and regional levels}

Acting on the UHC agenda at the country level requires difficult decisions. Policy makers must decide which services to expand, who to include as beneficiaries or service providers, and how to shift from out-of-pocket payment towards prepayment, and in what order, with a commitment to fairness and consideration of social needs and political realities. These policies and their implementation should be based on evidence and social values and be developed with public participation to ensure accountability. ${ }^{37}$

As there are multiple paths towards UHC, G20 members should document empirical lessons and good practices with robust research evidence and share the information with those who are responsible for implementing UHC in other countries. One example is Japan, where close collaboration between the ministries of health and finance, through periodic review of social insurance fee schedules, has enabled it to control overall expenditure while meeting the health needs of a rapidly ageing population. ${ }^{38}$ We recommend that G20 members support systematic studies of their own experiences with health finance and establish mechanisms for mutual learning about what works, how, and why, involving ministries of finance in addition to health.

We already have several global platforms, such as UHC2030's knowledge hub and the Joint Learning Network, which can be further strengthened. In addition, regional platforms, such as the regional observatories on health systems and policies, technical advisory groups on UHC or equivalent at WHO regional offices, and Association of Southeast Asian Nations (ASEAN+3) UHC network, should be enhanced to provide more timely and contextualised advice. G20 members should contribute to these mutual learning platforms and encourage their academic institutions, think tanks, and civil society organisations to participate.

\section{Coordination of international cooperation for sustainable UHC}

G20 members are the largest providers of development assistance, but increasing emphasis is being placed on mobilising domestic resources within developing countries to achieve the SDGs. ${ }^{39}$ G20 members should work together to help facilitate the transition of financing in developing countries, while harmonising their provision of technical assistance at country level, avoiding duplications and filling gaps. Figure 4 shows the typical experience of a recipient country. Multiple local ministries are responsible for various development sectors (health security, nutrition, etc) that often face overlapping but competing demands from dozens of supranational and national donors as well as international alliances, non-governmental organisations, and philanthropic partners in an uncoordinated way.

Recent G20 meetings have agreed on a coordinated global preparedness and response to health risks and on making connections and encouraging partnerships between international stakeholders and national governments, including those from non-G20 countries. ${ }^{40}$ Similarly, development partners should consider harmonising aid for progress towards UHC within the existing health sector aid coordination mechanism. The annual G20 health working group meeting could serve as an initial platform for such coordination. ${ }^{41}$ We do not underestimate the enormity of the challenge given shifting geopolitical alliances, the progressively inward outlook of individual countries, and their recent decisions to more closely link development aid with trade concerns as opposed to pursuing the common good as the over-riding objective.

\section{Conclusion}

Heads of state and government will attend a high level meeting on UHC at the United Nations General Assembly in September 2019. UHC will also be the theme of the 2020 Prince Mahidol Award Conference in Bangkok, along with the Second UHC Forum that will be held concurrently. G20 members should give renewed impetus to UHC progress and its timely achievement by 2030 , especially the four key areas considered here. Which, in what order and how each of these is prioritised will vary between and within countries. There is no one-size-fits-all solution, but tailored policies on the issues we have discussed must be developed through deliberate dialogue with civil society.

\section{Key messages \\ To achieve universal health coverage, primary healthcare systems should be bolstered while emphasising vulnerable groups, especially migrants, who experience substantial inequitable access \\ Strategic and innovative financing of healthcare, complemented by efficient deployment of resources, requires a whole government and cross-sector approach and should aim at self-sufficiency \\ Digital and other novel health technologies should be harnessed but their deployment must be judiciously regulated to ensure universal access \\ Governments and the broader global development community should collaborate more closely to establish common monitoring mechanisms, create mutual learning platforms, and harmonise international development aid \\ G20 is uniquely positioned to lead on these changes to accelerate progress towards universal health coverage}

We thank members of the working group on UHC, as well as expert contributors for participating in the Tokyo meetings in December 2018 (T20 inception conference) and February 2019, as well as helpful comments and suggestions on the various drafts of the policy brief by numerous rounds of electronic communication in a modified Delphi process. The working group members were Pascale Allotey, United Nations University-International Institute of Global Health, Malaysia; Agnes Binagwaho, University of Global Health Equity, Rwanda; Gerald Bloom, Institute of Development Studies, UK; Mina Chiba, Waseda University, Japan; Tomoko Fukuda, Japanese Organisation for International Cooperation in Family Planning (JOICFP), as representative of C20; Piya Hanvoravongchai, Chulalongkorn University, Thailand; Reiko Hayashi, National Institute of Population and Social Security Research, Japan; Ayako Honda, Sophia University, Japan; Mihoko Kashiwakura, Bill and Melinda Gates Foundation, Japan; Yasushi Katsuma, Waseda University, Japan; Masako Kikuchi, Japan International Cooperation Agency Research Institute, Japan; Sengchanh Kounnavong, Lao Tropical and Public Health Institute, Lao People's Democratic Republic; Soonman Kwon, Seoul National University, Republic of Korea; Gabriel M Leung (co-chair), University of Hong Kong; Saeda Makimoto, Japan International Cooperation Agency Research Institute; Walaiporn Patcharanarumol, International Health Policy Program, Ministry of Health, Thailand; Krishna D Rao, Johns Hopkins University, US; Gaurav Sharma, independent researcher and policy analyst, India; Tomohiko Sugishita, Tokyo Women's Medical University, Japan; Jason Dean-Chen Yin, University of Hong Kong; Yuta Yokohori, National Center for Global Health and Medicine, Japan. The expert contributors were J N Ahamarshan, independent researcher, India; Hirotsugu Aiga, Japan International Cooperation Agency; Sandro Galea, Boston University, US; S Raghavendra Guru, Independent researcher at Institute of Chartered Accountants of India; Masaki Inaba, Africa Japan Forum, as representative of C20, Japan; Mitsuo Isono, Japan International Cooperation Agency; T C James,

Research and Information System for Developing Countries, India; Ilona Kickbusch, Graduate Institute of International and Development Studies, Geneva, Switzerland; Kiyoshi Kodera, Overseas Development Institute, Japan; Hoang Van Minh, Hanoi University of Public Health, Vietnam; Rintaro Mori, United Nations Population Fund, Asia and the Pacific Regional Office, Thailand; Shintaro Nakamura, Japan International Cooperation Agency; Joji Sugawara, Health and Global Policy Institute, 
Japan; Tomoko Suzuki, Japan Center for International Exchange; Takao Toda, Japan International Cooperation Agency

Contributors and sources: This paper is based on the policy brief submitted by the T20 Working Group on UHC, which in turn is a part of Task Force 1 focusing on the SDGs. Japan holds the presidency of the 2019 G20, and the Japanese International Cooperation Agency Research Institute (JICA-RI) serves as the secretariat for T20. GML is co-chair of the Working Group and guarantor of the paper. SM is the administrative lead for JICA-RI. KDR, GB, YK, and SM wrote sections of the article. GML and JDCY compiled and edited the overall draft and created the graphics. All authors revised the draft and approved the final version. Competing interests: We have read and understood BMJ policy on declaration of interests and do not have any conflicts of interest to declare.

Provenance and peer review: Commissioned; externally peer reviewed.

1 Bloom G, Katsuma Y, Rao KD, Makimoto S, Leung G. Working Group on UHC of T20 Task Force 1. Deliberate next steps toward a new globalism for universal health coverage (UHC). 2019. https://t20japan.org/wp-content/uploads/2019/03/t20-japan-tf1-1-deliberatenext-steps-toward-new-globalism-for-uhc.pdf

2 Government of Japan, World Bank, World Health Organization, Unicef, JICA, UHC2030. Tokyo declaration on universal health coverage. Universal Health Coverage Forum 2017. https://www.who.int/universal_health_coverage/tokyo-decleration-uhc.pdf.

3 Mosquera PA, Hernández J, Vega R, etal . The impact of primary healthcare in reducing inequalities in child health outcomes, Bogotá-Colombia: an ecological analysis. Int J Equity Health 2012;11:66. 10.1186/1475-9276-11-66 23145972

4 Macinko J, Starfield B, Erinosho T. The impact of primary healthcare on population health in low- and middle-income countries. J Ambul Care Manage 2009;32:150-71. 10.1097/JAC.0b013e3181994221 19305227

5 Stigler FL, Macinko J, Pettigrew LM, Kumar R, van Weel C. No universal health coverage without primary health care. Lancet 2016;387:1811.

10.1016/S0140-6736(16)30315-4 27203497

6 Tam Y-H, Leung JYY, Ni MY, Ip DKM, Leung GM. Training sufficient and adequate general practitioners for universal health coverage in China. BMJ 2018;362:k3128. 10.1136/bmj.k3128 30049679

7 WHO. From primary health care to universal coverage - the "affordable dream". Ten years in public health, 2007-2017: report by Dr Margaret Chan, Director-General. Geneva: World Health Organization; 2017. https://www.who.int/publications/10-year-review/universalcoverage/en/

8 UN Department of Economic and Social Affairs Population Division. World population ageing 2017. 2017. https://www.un.org/en/development/desa/population/publications/pdf/ ageing/WPA2017_Report.pdf

9 Watkins D, Jamison D, Mills A, etal . Universal health coverage and essential packages of care. In: Disease control priorities. 3rd ed. World Bank, 201710.1596/978-1-4648-0527-1_ch3.

10 International Organization for Migration. Global migration indicators 2018. https:// publications.iom.int/system/files/pdf/global migration indicators_2018.pdf.

11 International Labour Organization. ILO global estimates on international migrant workers: results and methodology. 2018. https://www.ilo.org/wcmsp5/groups/public/---dgreports/-dcomm/---publ/documents/publication/wcms_652001.pdf

12 Zimmerman C, Kiss L, Hossain M. Migration and health: a framework for 21st century policy-making. PLoS Med 2011;8:e1001034. 10.1371/journal.pmed.1001034 21629681

$13 \mathrm{OECD/LO/IOM/UNHCR}$. G20 international migration and displacement trends report. 2018. http://www.oecd.org/els/mig/G20-international-migration-and-displacement-trendsreport-2018.pdf

14 Bilsborrow RE. The global need for better data on international migration and the special potential of household surveys. Migr Policy Pract. 2017;7:9-17.

15 Saint-Martin A, Inanc H, Prinz C. Job quality, health and productivity: an evidence-based framework for analysis. OECD Social, Employment and Migration Working Paper No 221. OECD, 2018.

16 Benach J, Muntaner C, Delclos C, Menéndez M, Ronquillo C. Migration and "low-skilled" workers in destination countries. PLoS Med 2011;8:e1001043. 10.1371/journal.pmed.1001043 21666784
17 Abubakar I, Aldridge RW, Devakumar D, etal. UCL-Lancet Commission on Migration and Health. The UCL-Lancet Commission on Migration and Health: the health of a world on the move. Lancet 2018;392:2606-54. 10.1016/S0140-6736(18)32114-7 30528486

18 Holzmann R. Do bilateral social security agreements deliver on the portability of pensions and health care benefits? A summary policy paper on four migration corridors between EU and non-EU member states 2016. http://ftp.iza.org/pp111.pdf

19 OECD. Health workforce migration-foreign-trained doctors by country of origin. OECD Stat 2017. https://stats.oecd.org/Index.aspx?Queryld=68336

20 OECD. Health workforce migration-foreign-trained nurses by country of origin. OECD Stat $2017 \mathrm{https}: / /$ stats.oecd.org/Index.aspx?Queryld=68336

21 World Health Organization. Migration of health workers: the WHO code of practice and the global economic crisis. 2014. https://www.who.int/hrh/migration/migration_book/en/

22 Cashin C, Sparkes S, Bloom D. Earmarking for Health From Theory to Practice. 2017.

23 Götze R, Schmid A. Healthcare financing in OECD countries beyond the public-private split. TranState working paper No 160. OECD, 2012.

24 Kutzkin J, Witter S, Jowett M, Bayarsaikhan D. Developing a national health financing strategy: a reference guide. 2017

25 Unami $\mathrm{H}$. The policy challenges of financing longevity-a perspective from Japan. J Econ Ageing 2018. [Epub ahead of print.] 10.1016/j.jeoa.2018.10.003

26 Review on Antimicrobial Resistance. Tackling drug-resistant infections globally: final report and recommendations 2016. https://amr-review.org/sites/default/files/160518_Final\% 20paper_with\%20cover.pdf

27 Bloom G, Merrett GB, Wilkinson A, Lin V, Paulin S. Antimicrobial resistance and universal health coverage. BMJ Glob Health 2017;2:e000518. 10.1136/bmjgh-2017-000518 29225955

28 World Health Organization. Technical series on primary health care brief: antimicrobial resistance and primary health care. 2018. https://www.who.int/docs/default-source/primaryhealth-careconference/amr.pdf?sfvrsn=8817d5ba_2.

29 Holloway KA, Kotwani A, Batmanabane G, Santoso B, Ratanawijitrasin S, Henry D. Promoting quality use of medicines in South-East Asia: reports from country situational analyses. BMC Health Serv Res 2018;18:526. 10.1186/s12913-018-3333-1 29976180

30 OECD. ICTs and the health sector: towards smarter health and wellness models. 2013. www.oecd.org/sti/ieconomy/ict-and-the-health-sector.htm

31 National Academy of Sciences, Engineering, and Medicine. Crossing the global quality chasm: improving health care worldwide. National Academies Press, 2018.

32 Agarwal S, Perry HB, Long L-A, Labrique AB. Evidence on feasibility and effective use of mHealth strategies by frontline health workers in developing countries: systematic review. Trop Med Int Health 2015;20:1003-14. 10.1111/tmi.12525 25881735

33 Free $\mathrm{C}$, Phillips $\mathrm{G}$, Watson $\mathrm{L}$, etal . The effectiveness of mobile-health technologies to improve health care service delivery processes: a systematic review and meta-analysis. PLoS Med 2013;10:e1001363. 10.1371/journal.pmed.1001363 23458994

34 Wilson K, Gertz B, Arenth B, Salisbury N. The journey to scale: moving together past digital health pilots. 2014. https://path.azureedge.net/media/documents/TS_dhs_journey_ to_scale.pdf

35 Bloom G, Berdou E, Standing H, Guo Z, Labrique A. ICTs and the challenge of health system transition in low and middle-income countries. Global Health 2017;13:56. 10.1186/s12992-017-0276-y 28784144

36 Balasubramaniam P, Rao N, Sharma G, et al. Innovations for universal health coverage: a south-south collaboration to transform health systems in Africa and India. 2018. https: //opendocs.ids.ac.uk/opendocs/handle/123456789/14180

37 World Health Organization. Tracking universal health coverage: 2017 global monitoring report. 2017. https://www.who.int/healthinfo/universal health coverage/report/2017/en/

38 Hashimoto $\mathrm{H}$, Ikegami $\mathrm{N}$, Shibuya $\mathrm{K}$, etal . Cost containment and quality of care in Japan: is there a trade-off? Lancet 2011;378:1174-82. 10.1016/S0140-6736(11)60987-2 21885098

39 UHC 2030. Statement on sustainability and transition from external funding . 2018. https: //www.uhc2030.org/fileadmin/uploads/uhc2030/Documents/About_UHC2030/UHC2030_ Working_Groups/2017_Transition_working_group_docs/UHC2030_Statement_on sustainability_and_transition_Oct_2018.pdf

40 G20 Health Ministers. Declaration: G20 Meeting of Health Ministers. Buenos Aires, 2018. http://www.g20.utoronto.ca/2018/2018-10-04-health.html

41 World Health Organization. Towards a global action plan for healthy lives and well-being for all: uniting to accelerate progress towards the health-related SDGs. 2018. https://www. who.int/iris/handle/10665/311667.

Published by the BMJ Publishing Group Limited. For permission to use (where not already granted under a licence) please go to http://group.bmj.com/group/rights-licensing/ permissions This is an Open Access article distributed in accordance with the Creative Commons Attribution Non Commercial (CC BY-NC 4.0) license, which permits others to distribute, remix, adapt, build upon this work non-commercially, and license their derivative works on different terms, provided the original work is properly cited and the use is non-commercial. See: http://creativecommons.org/licenses/by-nc/4.0/. 


\section{Figures}

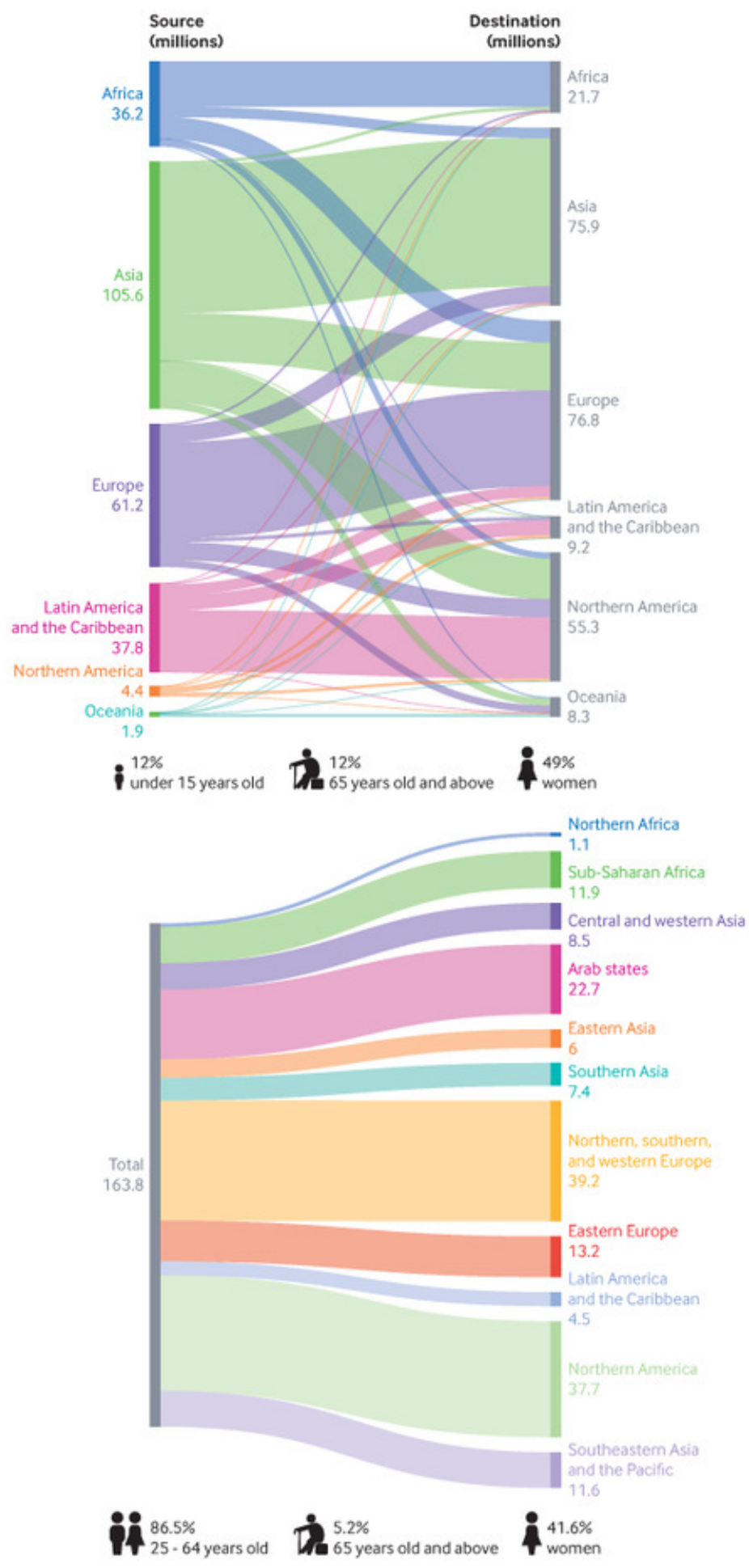

Fig 1 Total migration by source and destination region in $2017^{10}$ and total labour migration by destination region in $2017^{11}$ 


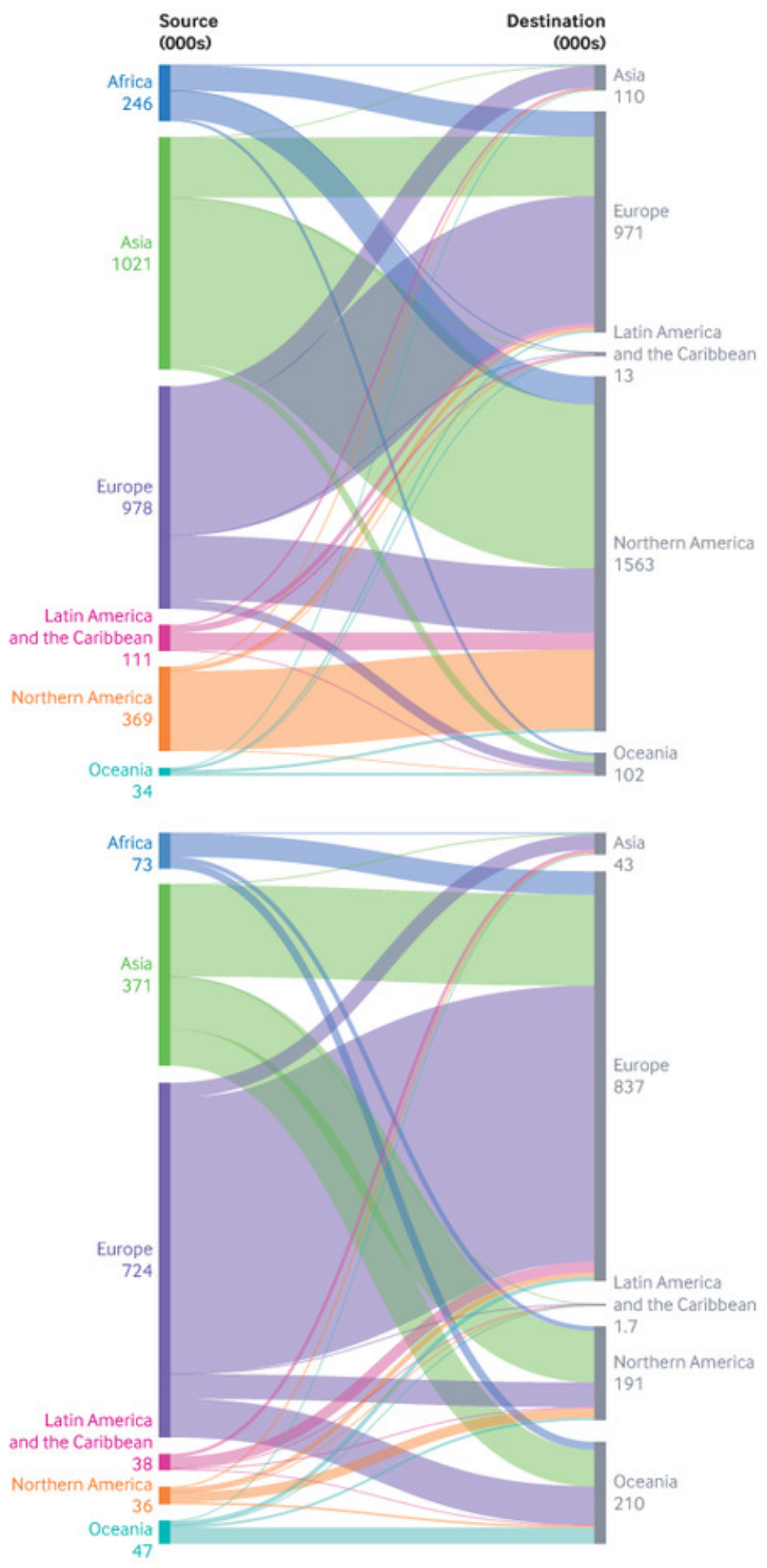

Fig 2 Numbers of foreign trained doctors (left) and nurses (right) by Organisation for Cooperation and Development regions, $2012-16^{1920}$ 


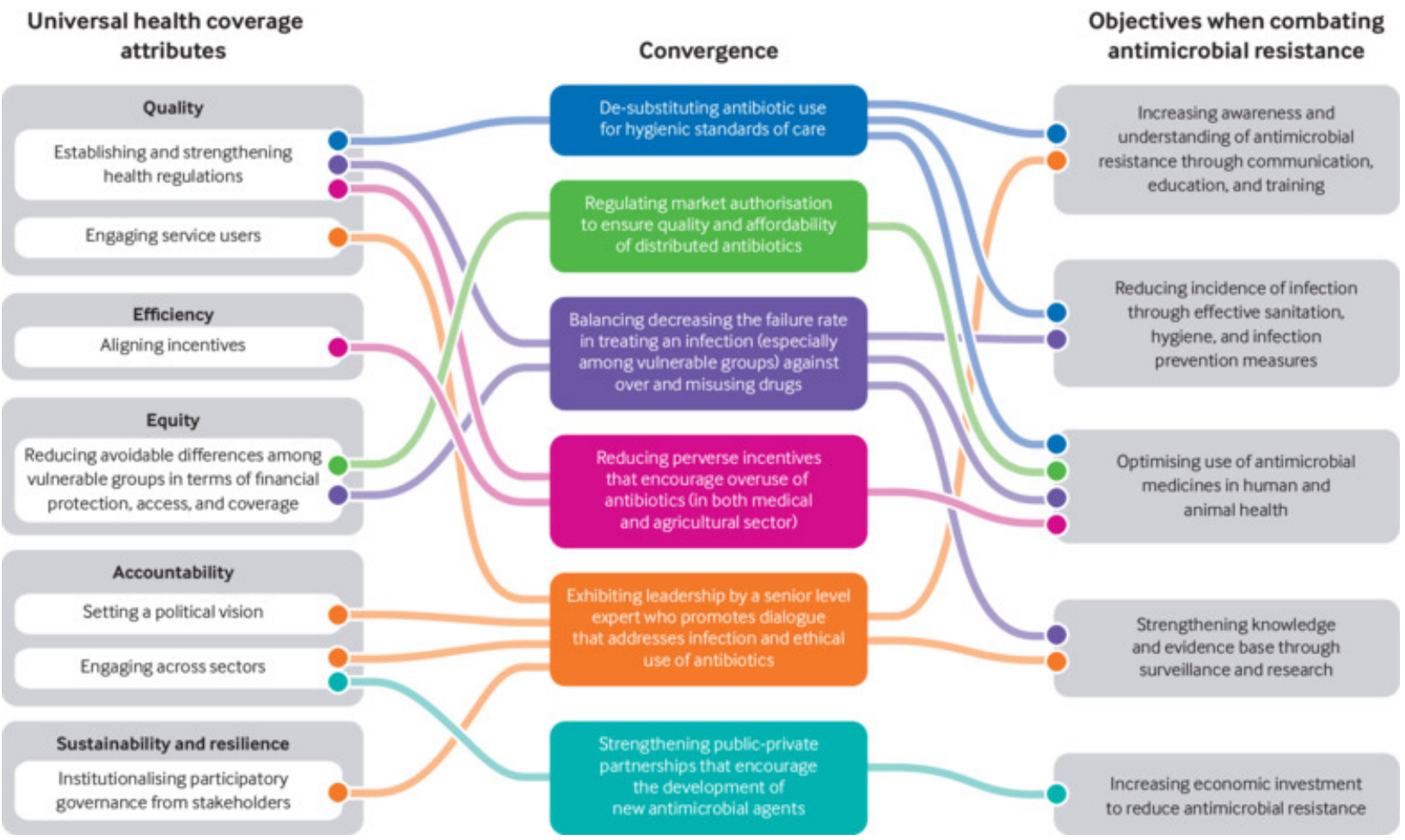

Fig 3 Convergence of action plans for universal health coverage and infectious diseases: example of WHO Western Pacific Region universal health coverage action framework (left) and the WHO antimicrobial resistance global action plan (right) 


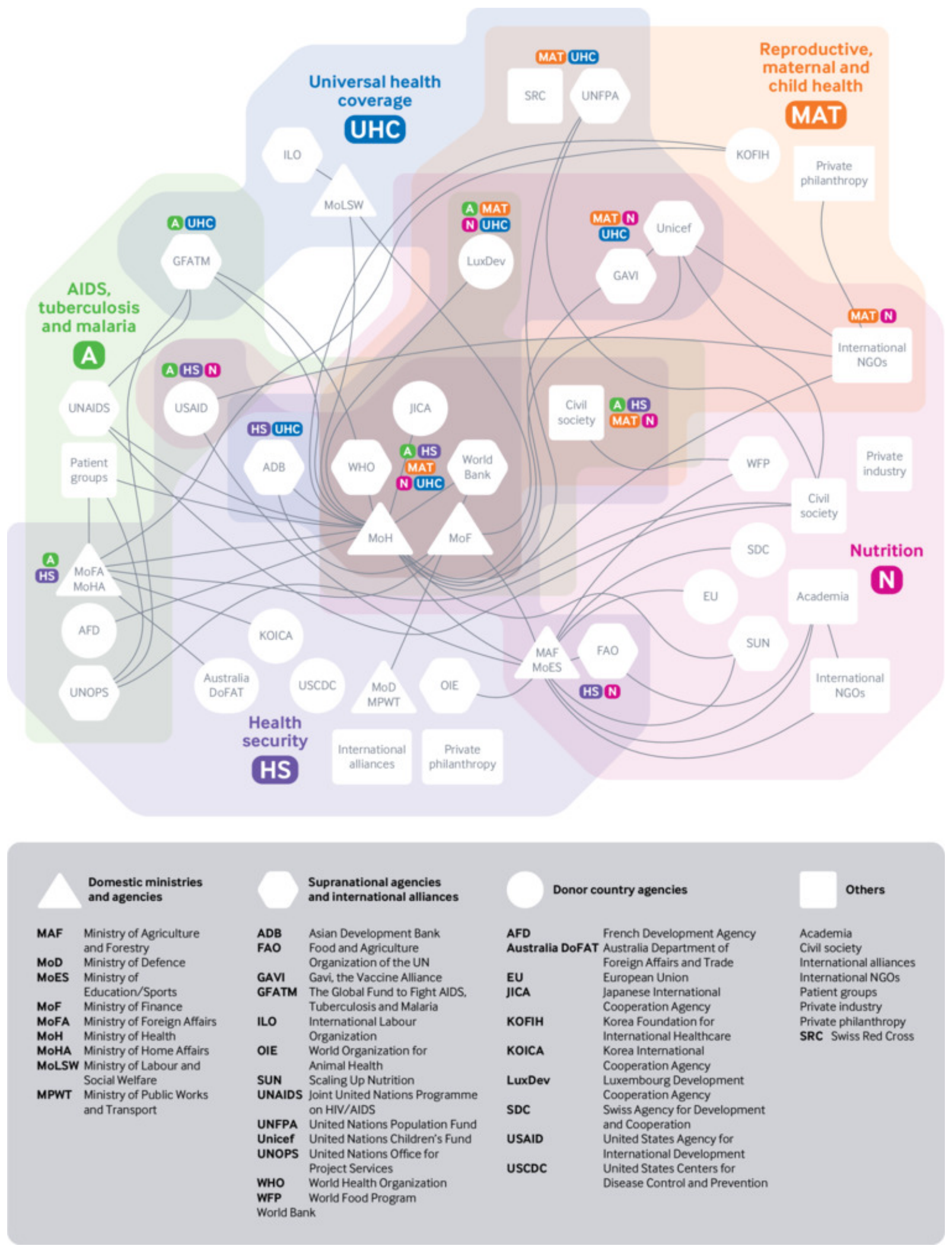

Fig 4 Congestion and gaps in a complex web of global health development aid in a typical recipient country 